\title{
8
}
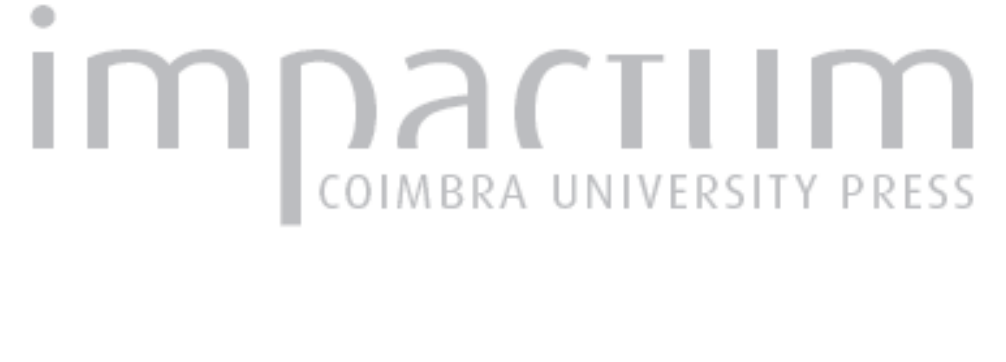

\section{Hegemonia do masculino e triunfo do feminino no romance Buddenbrooks de Thomas Mann}

\author{
Autor(es): Boura, Ana Isabel
}

Publicado por: $\begin{aligned} & \text { Faculdade de Letras da Universidade de Coimbra, Instituto de Estudos } \\ & \text { Filosóficos }\end{aligned}$

URL

persistente:

DOI:

URI:http://hdl.handle.net/10316.2/33391

Accessed : $\quad$ 26-Apr-2023 12:03:57

A navegação consulta e descarregamento dos títulos inseridos nas Bibliotecas Digitais UC Digitalis, UC Pombalina e UC Impactum, pressupõem a aceitação plena e sem reservas dos Termos e Condições de Uso destas Bibliotecas Digitais, disponíveis em https://digitalis.uc.pt/pt-pt/termos.

Conforme exposto nos referidos Termos e Condições de Uso, o descarregamento de títulos de acesso restrito requer uma licença válida de autorização devendo o utilizador aceder ao(s) documento(s) a partir de um endereço de IP da instituição detentora da supramencionada licença.

Ao utilizador é apenas permitido o descarregamento para uso pessoal, pelo que o emprego do(s) título(s) descarregado(s) para outro fim, designadamente comercial, carece de autorização do respetivo autor ou editor da obra.

Na medida em que todas as obras da UC Digitalis se encontram protegidas pelo Código do Direito de Autor e Direitos Conexos e demais legislação aplicável, toda a cópia, parcial ou total, deste documento, nos casos em que é legalmente admitida, deverá conter ou fazer-se acompanhar por este aviso.

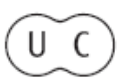




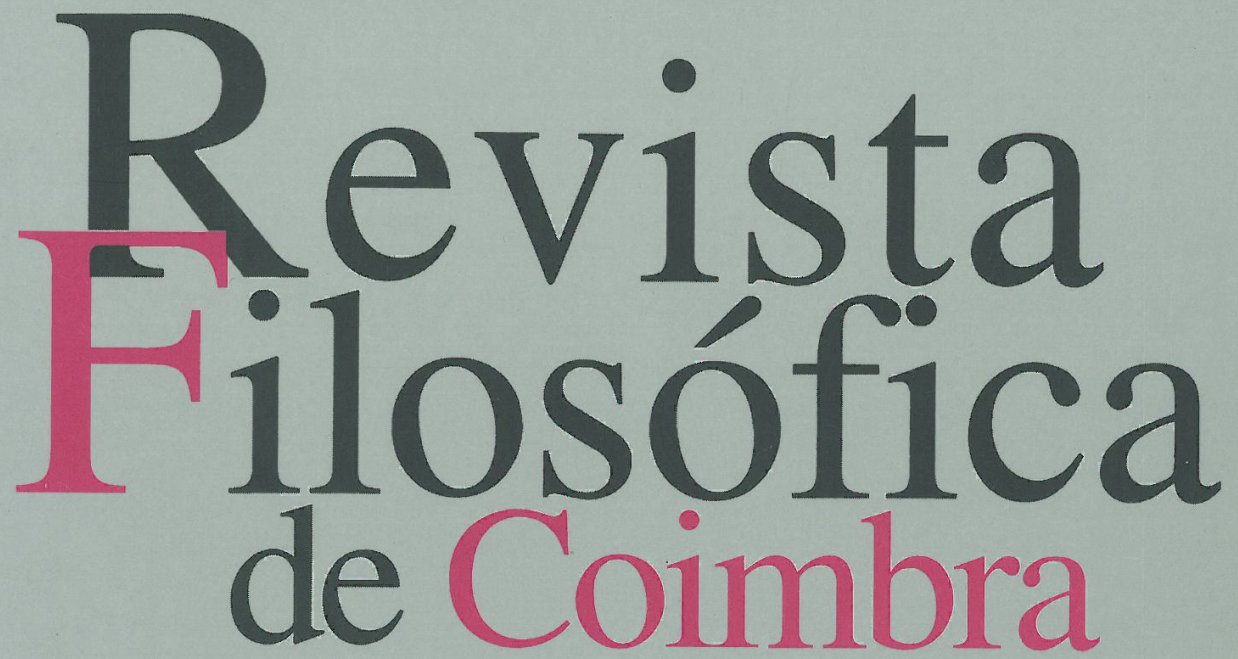

vol.17 | n.34 | 2008

José Reis

Manuel Moreira da Silva Helder Gomes

Filipe P. S. M. Menezes Edmundo Balsemão Maria João Silveirinha Luís António Umbelino Cláudio Alexandre S. Carvalho Armindo dos Santos Ana Isabel Boura Regina Queiroz Dulce Morgado Neves 


\title{
HEGEMONIA DO MASCULINO E TRIUNFO DO FEMININO NO ROMANCE BUDDENBROOKS DE THOMAS MANN
}

\author{
ANA ISABEL GOUVEIA BOURA
}

(Universidade do Porto)

Como o título e o subtítulo deixam antever, Buddenbrooks. Verfall einer Familie (Buddenbrooks. Decadência de uma Família), de Thomas Mann, narra a história de uma família alemã setentrional oitocentista afectada por irreversível processo de decadência biológica, psicológica, económica e social. No decurso de quatro décadas, entre 1835 e 1877, ocorre o movimento declinante de quatro gerações buddenbrookianas. Assim, enquanto Johann Buddenbrook sénior promove o incremento da firma homónima de cereais e consolida a imagem social da família alto-burguesa hanseática, o filho Jean não evita a diminuição ligeira do capital da empresa, os netos Thomas, Tony, Christian e Clara abalam o património familiar e o bisneto Hanno determina a extinção da estirpe.

Concluído em 1900 e publicado no ano seguinte, vindo a justificar a atribuição, em 1929, do Prémio Nobel da Literatura ao autor lübeckiano, o romance situa-se na confluência das estéticas realista, naturalista, esteticista e decadentista, conjugando os vectores temático-motívicos que então sobressaíam na literatura europeia: a interacção precária de indivíduo, família e sociedade, a relação conflituosa de burguesia e arte, a fronteira esbatida dos géneros masculino e feminino.

Não surpreende, assim, que o primeiro romance de Thomas Mann, centrado, embora, no clã titular, delineie múltiplas formas de família, desenhe concomitantes trajectórias de ascensão e declínio e insinue distintas motivações de decadência familiar. De facto, o leitor de Buddenbrooks vê-se confrontado com sucessivos quadros de família alargada, restrita e monoparental, em simultâneas dinâmicas de prosperidade e desventura familiares, sendo convidado a reconhecer que não tanto circunstâncias externas, mas sobretudo condicionalismos internos proporcionam o descalabro da família protagonista: os membros 
Buddenbrook sucumbem ao modelo patriarcal, com que voluntariamente pautaram a encenação intrafamiliar.

\section{Sob a égide do modelo patriarcal}

Buddenbrooks actualiza, na constelação protagonista, o modelo oitocentista do patriarcado, que subpõe ao chefe de família, tutelar e provedor, a dama da casa, submissa e mediadora, e os filhos, comprometidos com a tradição dinástica. De facto, se ao pater familias buddenbrookiano compete o sustento, pelo labor extradomiciliário, dos membros que acolhe no seu espaço residencial - parentes directos e colaterais, serviçais e escriturários -, à esposa cabe a gestão doméstica, o acolhimento do marido, a supervisão dos filhos e a representação social, cumprindo aos filhos varões a formação académica adequada à sua futura actividade na firma e às filhas a realização de uma proveitosa aliança matrimonial.

Já a cena inicial do romance deixa perceber a organização patriarcal da família titular: avós, pais e neta aguardam, com a sobrinha pobre e a governanta fiel, no salão da moradia patrícia, a chegada dos filhos varões e de proeminentes convidados, para festejarem a recente transferência domiciliária. Lado a lado no sofá, Madame Antoinette e a nora Elisabeth, acatam, como o filho Jean, em poltrona próxima da esposa, a argumentação de Johann Buddenbrook sénior, sentado à janela, com Tony, a neta mais velha, no colo. ${ }^{1}$ Nos interstícios das réplicas patriarcais, filho e nora activam a sua função pedagógica: Elisabeth encoraja a pequena Tony a recitar o comentário oficializado ao primeiro artigo do catecismo evangélico e Jean incita a filha a adoptar a postura diligente da prima Klothilde.

Também a subsequente cena da refeição comemorativa faz jus ao modelo patriarcal: no lado honorífico da mesa, acomoda-se, não o patriarca anfitrião, mas Lebrecht Kröger, o parente com idêntico estatuto no ramo colateral, que cavalheirescamente atende as senhoras que o ladeiam - a anfitriã e a esposa do único convidado com título senatorial. Aos assuntos de interesse comum (história da mansão inaugurada e da família anfitriã) seguem-se temas específicos do género masculino (negócios, política local) e matérias convencionalmente femininas (receitas de cozinha).

${ }^{1}$ A posição periférica do patriarca familiar não atenua, antes reforça o seu estatuto hegemónico, pois que lhe garante uma visão panorâmica, e, por conseguinte, dominadora, dos espaços interior e exterior. 
Tal diferenciação genérica acentua-se no termo do banquete, que, formalmente assinalado pelo anfitrião, impõe a cisão do grupo confraternizante: ao salão regressam as senhoras, na companhia dos dois patriarcas familiares, do poeta de circunstância e do Pastor, para aí desfrutarem do prometido entretenimento musical; à sala de bilhar, no edifício traseiro, dirigem-se os restantes cavalheiros, conduzidos por Jean, que, deste modo, obedece à incumbência paterna de substituição. Ao divertimento do jogo associa-se a recreação da conversa que o cadencia - temas da política e da economia locais, prontamente rejeitados em favor da quadra brejeira ou dos aforismos jocosos enunciados pelo poeta, que, com o clérigo, entretanto assoma na sala. ${ }^{2}$

Análoga configuração patriarcal evidencia a cena da primeira visita de Bendix Grünlich, futuro marido de Tony, à família Buddenbrook. Reunidos no jardim da mansão patrícia, pai, mãe, filhos e sobrinha fruem a amenidade de uma tarde veranil; Jean, o novo patriarca da família, entrega-se à leitura do jornal, que lhe amplia a competência profissional; Elisabeth ocupa-se com um trabalho de lavores, que aprimorará o apetrechamento decorativo da residência; Christian, o varão mais jovem, exercita os conhecimentos de Latim; Tony e Klothilde entretêm-se com romances sentimentais; e Clara, a filha mais nova, brinca no relvado, sob observação materna. Nas intermitências dialógicas, o chefe da firma anuncia a Thomas, o filho primogénito, a iminente realização de um negócio lucrativo e a mãe sugere à filha em idade casadoira o traje para o próximo baile social.

O modelo do patriarcado molda igualmente o quadro familiar que antecede a morte de Jean. No salão da casa buddenbrookiana, Elisabeth, Thomas, Tony, Clara e Klotilde esperam a descida do patriarca, para um passeio dominical a zona suburbana: enquanto a dama da casa e a filha mais velha partilham o sofá e a filha mais nova se acomoda, com a prima, junto da janela, o futuro patriarca da terceira geração instala-se em poltrona próxima da mãe, fumando um cigarro.

$\mathrm{O}$ estatuto patriarcal dos primogénitos buddenbrookianos legitima-lhes, como assinalam Jochen Vogt (1983: 44), Eric Herd (1988: 215, ou Elisabeth Boa (1995: 128), o exercício de severa autoridade: Johann Buddenbrook sénior não se coíbe em reprovar o neto Christian, na festa da inauguração domiciliária, pelo momentâneo desregramento alimentar; Jean não hesita em negar à esposa a contratação de um criado adicional, ou em impôr a Tony um casamento de conveniência; Thomas não transige

2 Tal divisão grupal caracterizava, como Gustav Lindtke (1975: 50; 1981: 61) informa, os serões conviviais da alta burguesia hanseática. 
na exigência de que Gerda acompanhe o marido nos passeios familiares, nem no interrogatório, às refeições principais, de Hanno sobre a toponímia e a demografia locais, ou a estrutura da firma familiar.

Claro que o rigor do modelo patriarcal afecta menos os sujeitos masculinos, do que as figuras femininas: com a livre movimentação interlocal dos cavalheiros contrasta, no conjunto buddenbrookiano, o retraimento físico e psíquico das damas. Assim, Johann Buddenbrook sénior atravessa o Sul da Alemanha em carruagem carregada de mercadorias; Jean ruma à Escócia e a Inglaterra, em viagem de negócios, e a Obersalzbrunn, Ems, Baden-Baden, ou Kissingen, para tratamento termal; Thomas desloca-se à Holanda, para estágio comercial, a Pau e a Bad Kreuth, em requisição de hidroterapia, e a Amsterdão, com propósito negocial; Christian dirige-se a Londres, para formação profissional, a Valparaiso, em alegada actividade laboral, a Bad Oyenhausen, para cura termal, e a Hamburgo, para internamento hospitalar. Na urbe local, os varões Buddenbrook ingressam sem restrição no Círculo de Leitura, no Clube, ou no bordel.

Em contrapartida, Elisabeth acompanha o patriarca em deslocações a Marienbad, a Paris e à Suíça, ou em viagens por Nuremberga, Munique, Salzburgo, Viena, Praga, Dresden e Berlim; Tony desloca-se, por exigência paterna e sob escolta do irmão primogénito, a Travemünde e transfere-se, por imposição conjugal, para as imediações de Hamburgo e para Munique; Clara junta-se ao marido em Riga. Na cidade natal, Elisabeth e as filhas preenchem o quotidiano com trabalhos manuais, que favorecem o orçamento doméstico, ou com a leitura de romances inócuos, que lhes sublimam o erotismo reprimido, deixando o espaço residencial quase sempre na companhia dos membros masculinos, para assistirem a missa dominical na igreja que se ergue defronte da casa, se apresentarem em bailes promovidos pelas famílias proeminentes da urbe, ou realizarem digressões suburbanas.

Não obstante, os Buddenbrook unem-se no propósito de salvaguardar o nome e o património da família. Perspectivando o sujeito como elo de cadeia multissecular, avós, pais e filhos dispõem-se a submeter os interesses do indivíduo às conveniências do grupo. Daí a promoção de actos ritualísticos, que atestam e reforçam a coesão e a continuidade familiares. Neste sentido, Johann Buddenbrook sénior não prescinde da festa inaugurativa, que agrega parentes locais, amigos íntimos e conhecidos proeminentes e retoma, no novo domicílio, os encontros familiares das Quintas-Feiras, que juntam ramos directos e colaterais da árvore buddenbrookiana; Jean e Elisabeth reúnem patrões e empregados nas orações quotidianas e franqueiam a moradia da Mengstraße a nãoresidentes nas celebrações de Natal, nas cerimónias nupciais e nos actos 
fúnebres; e Thomas não se escusa a festejar, em família restrita ou alargada, a véspera de Natal, a mudança para a casa na Fischergrube, o oitavo aniversário do filho e o jubileu da firma cerealífera.

Em prol da harmonia familiar, punem-se as opções transgressoras: Johann Buddenbrook sénior castiga Gotthold, o filho de primeiras núpcias, pelo seu casamento por amor com a filha de um pequeno comerciante, ditando-lhe a exclusão do círculo familiar, diminuindo-lhe a quota-parte no legado patrimonial e sonegando-lhe o direito à sucessão na chefia da firma. Com a severidade prepotente da instância paterna contrasta a benevolência transigente da figura materna, pronta a dissimular as erupções conflituosas: Antoinette sugere a Jean que adie a revelação ao pai da carta reivindicativa endereçada pelo meio-irmão Gotthold; Elisabeth intervém apaziguadoramente nas desavenças de Thomas e Christian; Gerda Buddenbrook condescende que Hanno entre furtivamente na sala de música e se inebrie com a execução, a solo ou em dueto, da mãe.

Em consonância com a matriz patriarcal que estrutura e dinamiza a vivência familiar dos Buddenbrooks, o narrador concede, como sublinham Patricia Dechsel Tobin (1976: 54), Norman Roessler (1995: 150) e Walter Erhart (2001: 288; 2004: 174), primária atenção aos membros varões, actuais ou potenciais chefes da família, privilegiando não apenas o seu retrato e a sua actuação, mas também o respectivo espaço domiciliário: a história dos quatro membros varões sustenta e direcciona o eixo central do romance. ${ }^{3}$

\section{Claudicação dos membros masculinos}

O estatuto patriarcal privilegia os primogénitos Buddenbrook, mas não os imuniza à fragilização que afecta os restantes varões da família. Divididos entre as preferências individuais e os interesses familiares, os chefes da família Buddenbrook sucumbem, ao lado dos membros masculinos por que se responsabilizam. Com a cumplicidade da instância narratorial, que gradativamente transfere o foco perspectívico do cenário externo para o universo interior das personagens, o leitor assiste ao progressivo esbatimento da vitalidade buddenbrookiana.

De facto, Johann Buddenbrook sénior afirma-se pelo impulso vital, que o rosto redondo e levemente rosado anuncia e o dinamismo profissional confirma. Herdeiro da mundividência secular, pragmática e

${ }^{3} \mathrm{O}$ próprio Thomas alude retrospectivamente à preponderância da linha masculina, em Buddenbrooks, ao afirmar, em 1925, no ensaio Über die Ehe, que o romance trata "do casamento e da paternidade" ("von der Ehe und Vaterschaft", Mann, 1990b: 199). 
optimista que informou o Século das Luzes, o patriarca da primeira geração equilibra labor e entretenimento, promovendo o incremento da firma, sem deixar de fruir o aconchego da família e a animação da sociedade. Nem a redução do capital acumulado, pela subtracção das quantias destinadas ao dote matrimonial da filha e ao estabelecimento profissional do filho primogénito, desanimam o primeiro chefe familiar, que morre em avançada idade, velado pelos descendentes e enunciando serenas frases de incentivo e de orientação aos membros varões.

Do antecessor difere Jean, não apenas pela fragilidade somática, prefigurada nas patologias da infância e da adolescência, sinalizada nas linhas vincadas do rosto oval e manifesta nas enfermidades da idade adulta, mas igualmente pelo pendor introspectivo e pela convicção pietista. Disposto a realizar a incumbência paterna de dignificar o nome, preservar a tradição e ampliar o património familiares, Jean exacerba o afinco profissional, familiar e cívico, oscilando entre as prioridades da actividade comercial e os imperativos da devoção religiosa. Tal posição dilemática justifica, por um lado, a prontidão com que Jean desposa a requintada Elisabeth Kröger, o esmero com que franqueia a Thomas e Christian as rotas da actividade empresarial e a obstinação com que providencia o casamento e o divórcio de Tony; e explica, por outro lado, que, na festa da inauguração, após a refeição comemorativa, Jean assuma a custo a delegação paterna de conduzir os cavalheiros à sala de bilhar, reprimindo o impulso de se instalar no salão, para fruir o programa musical destinado ao grupo feminino, e que o chefe familiar se deixe ludibriar pelas réplicas lisonjeiras e pelos relatórios infundados do pretendente Grünlich, ou que faleça, num Domingo, sozinho no quarto conjugal, quando uma tempestade desaba sobre o burgo hanseático.

Com a robustez do avô e a tenacidade do pai contrasta a labilidade física e psíquica de Thomas. Não que o terceiro patriarca desmereça o legado familiar; pelo contrário, o filho de Jean e Elisabeth acelera e amplia a trajectória ascendente da firma e da família, juntando à modernização da empresa cerealífera a próspera aliança matrimonial, o nascimento de um herdeiro varão, a transferência para faustosa residência vicarial e a prestigiante eleição para o Senado. A Thomas falta, porém, o impulso genuíno que moveu os antepassados: o zelo com que age na esfera laboral, no círculo familiar, ou no universo social desgasta-o, denunciando-lhe o perfil não de "homem activo" ("tätiger Mann", Mann, 1990: 470), mas de "pensador escrupuloso" ("skrupulöser Nachdenker", ibid., 469) e "terno sonhador" ("zärtlicher Träumer" ibid., 470).

Acabrunhado por múltiplos lances de adversidade empresarial e familiar, que lhe exacerbam os acessos de conflito interior, Thomas negligencia a actividade profissional, a actuação familiar e a intervenção 
cívica, abandonando amiudadamente o escritório da firma, para se entregar aos sons balsâmicos do jardim, diminuindo progressivamente as celebrações privado-domésticas e teatralizando obstinadamente as aparições sócio-políticas. No agravamento da sintomatologia neurótica, que lhe enquadra a palidez do rosto, a frialdade das mãos, a disfunção pulmonar, a falta de apetite, de equilíbrio e de sono, a dependência do tabaco e a obsessão da higiene, a postura misantropa e o impulso depressivo, o terceiro chefe buddenbrookiano busca, em vão, lenitivo na poesia e na filosofia, determinando testamentariamente a liquidação da firma $>$ Johann Buddenbrook $<$ e sucumbindo ao acidente vascular-cerebral que o derruba na via pública.

Em Christian surgem amplificadamente os traços de debilidade físico-psicológica que afloram em Jean e assomam em Thomas. Ressaltam, assim, por um lado, os sinais de descompensação somática: a astenia, sugerida pela palidez e maceração do rosto, e o reumatismo, apenas aliviado por cíclicos tratamentos termais e hospitalares. Avultam, por outro lado, as marcas de desequilíbrio mental: a postura ansiosa, a propensão hipocondríaca, o pendor abúlico, o impulso alienatório, a expressão inconveniente. Bem cedo indicia, aliás, Christian tais disfunções, por de mais prefiguradas pela indisposição gástrica que o acomete na festa da inauguração, pela convicção de que um caroço de pêssego lhe obstrui a garganta, pelo seu desaproveitamento escolar, pela sua apurada imitação de gestos e discursos circundantes. Vãmente providencia Jean ao segundo filho um estágio comercial em Londres: avesso aos mecanismos de calibração familiar, hostil aos padrões de comprometimento laboral e amante dos artefactos teatrais e circenses, o neto de Johann Buddenbrook sénior troca o reduto doméstico ora pelos núcleos licenciosos do burgo, ora pelos recessos lúdicos de Valparaíso, Londres e Hamburgo, promovendo o deslustre do nome e a delapidação do património familiares.

Hanno distingue-se pela compleição débil, quase feminina, que, evidente nos traços delicados da fisionomia, ou nos brandos contornos dos membros, lhe insinua a saúde periclitante. De facto, sobrevivente de parto laborioso, o filho de Thomas acusa patologias do foro estomatológico, endocrinológico, cardiológico e gastroenterológico, que lhe afectam o desenvolvimento bio-psíquico-social: a fragilidade estrutural do quarto primogénito buddenbrookiano, mal combatida pelas sucessivas intervenções clínicas e farmacológicas, favorece-lhe a improdutividade escolar, a incompetência relacional, mas também a predisposição artística. Intimidado pela austeridade do pai, pela prepotência dos professores e pela rudeza dos colegas, Hanno encontra alívio na extremosa dedicação da avó, da mãe, da tia e da governanta, na fogosidade amorosa do amigo 
Kai e na gratuitidade orgiástica da música. Mas o impulso estético que o resgata do espartilho familiar e social sacrifica-lhe a escassa vitalidade orgânica, induzindo-lhe fantasias de morte redentora: acometido pelo tifo, Hanno evade-se, em voluptuoso abandono, confirmando o traço duplo que intuitivamente subpusera ao seu nome nos cadernos de família, o repertório multissecular da história buddenbrookiana.

À gradual fragilização dos varões Buddenbrook associa-se o decréscimo sucessivo da sua longevidade e a crescente contundência da sua morte. De facto, os representantes masculinos da família titular não só atingem cada vez mais cedo o seu limite existencial, tocando o índice da crassa precocidade, como também sucumbem a patologias de complexidade progressiva. Deste modo, enquanto Johann Buddenbrook sénior cede, aos setenta e sete anos, em branda agonia, a uma ligeira constipação, Gotthold não resiste, aos sessenta anos, a súbita crise cardiopática, Jean sofre, aos cinquenta e cinco anos, a agonia breve de um ataque cardíaco, Thomas perece aos quarenta e nove anos, em lenta agonia, após colapso vascular-cerebral, e Hanno falece aos quinze anos, depois de demorada crise tifóide. Que a morte dos cinco membros buddenbrookianos ocorra respectivamente no termo do Inverno, no final da Primavera, no fim do Verão, e, nos dois últimos casos, em pleno Inverno acentua a isotopia da desvitalização masculina.

\section{Afirmação dos membros femininos}

À progressiva debilitação das personagens masculinas contrapõe-se, na esfera buddenbrookiana, a contínua resiliência das figuras femininas. Sujeitas, embora, aos espartilhos do figurino patriarcal, as representantes da família protagonista assumem a postura da submissão, para melhor exercerem o gesto da assertividade. Conformadas com o papel secundário de consortes solícitas ou de filhas obedientes, que lhes estreita o horizonte vivencial, as mulheres Buddenbrook contracenam habilmente com os chefes familiares, favorecendo-lhes os lances e corroborando-lhes os propósitos, sem se deixarem contaminar pela fragilidade que os vence.

De facto, Madame Antoinette realiza cabalmente a expectativa patriarcal de respeito, mediação e representação. Na festa inaugurativa, a dama da primeira geração aplaude as réplicas do marido com um riso divertido que copia o riso prazenteiro de Johann Buddenbrook sénior; persuade Jean a sonegar ao pai, até ao termo do convívio festivo, a informação sobre a carta reivindicativa de Gotthold; e, sentada à mesa entre o sogro do filho e o prelado da igreja fronteira, atende ao diálogo das convidadas, enquanto observa rigorosamente as manobras da 
criadagem. E, contudo, Antoinette abala indelevelmente, pela sua morte - a primeira ocorrência necrológica na casa da Mengstraße - a dinâmica familiar, pois que à remodelação cénica imposta pelo velório se junta a alteração comportamental do viúvo, que, em breve, cede a propriedade e a gestão da firma cerealífera ao filho herdeiro, confinando-se, em silenciosa contemplação, ao reduto doméstico, e, pouco depois, se desvincula da existência.

Não menos modelarmente cumpre Elisabeth as funções que os códigos familiares da burguesia oitocentista reservam ao seu estatuto de esposa e mãe. Com a mesma docilidade com que secunda os rituais domésticos implementados pelo marido, auxilia a primeira dama da segunda geração o cônjuge na persuasão de Tony a um casamento de conveniência. Após a morte do marido, que em testamento designa a viúva herdeira universal, Elisabeth assume, com firme zelo, as responsabilidades de mater familias. Assim, a esposa de Jean não só mantém os convívios grande-familiares das Quintas-feiras, como até intensifica e diversifica as práticas devotas impostas aos habitantes da mansão patrícia: às orações matinais e vesperais e às celebrações de Natal, ampliadas no horário e na estrutura, juntam-se as sessões de educação catequética, as reuniões femininas de beneficiência, as recepções de prelados e missionários. E tanto, quanto preserva a memória do marido, salvaguarda Elisabeth a harmonia e a coesão dos descendentes, franqueando a casa da Mengstraße aos futuros cônjuges de Tony, Thomas e Clara, promovendo a integração de Christian na firma cerealífera, serenando Tony na desavença com o segundo marido Alois Permaneder, apaziguando a mútua animosidade dos filhos varões.

Ciosa das prerrogativas matriarcais, Elisabeth não hesita em refrear os impulsos hegemónicos de Thomas, incitando-o a admitir o irmão mais novo no quadro laboral da empresa buddenbrookiana e anuindo, sem consulta prévia do filho primogénito, ao pedido da recém-falecida Clara, que, em jeito de despedida, reclama a cedência ao marido da sua quotaparte na herança familiar. Debalde invoca Thomas, agastado com a manobra fraudulenta do cunhado, a sua autoridade de chefe varão e de representante paterno: Elisabeth contrapõe-lhe a sua soberania de matriarca. Acometida por doença bronco-pulmonar, a senhora Buddenbrook busca tenazmente a sobrevivência, retardando, em exacerbado impulso vital, a progressão da enfermidade e sucumbindo após lentíssima agonia.

Com vigorosa determinação persegue Tony o incumbido engrandecimento do nome e do património familiares. Já em adolescente, a filha de Jean e Elisabeth manifesta o firme propósito de contrair uma proveitosa aliança matrimonial, sugerindo paralelamente à requintada colega Gerda Arnoldsen o casamento com o primogénito Thomas Buddenbrook. E, de 
facto, não faltam predicados de "bom partido" nem ao próspero agente comercial Grünlich, que Tony prefere a Morten, o amado estudante de Medicina, nem ao grande comerciante Permaneder, com quem a herdeira Buddenbrook casa para reparar o fracasso do primeiro matrimónio, nem a Hugo Weinschenk, o director comercial que a filha Erika desposa com a entusiasmada aprovação materna. Só o atentado dos três cavalheiros contra a ética e a fortuna buddenbrookianas, que, aliás, exaspera a forte vinculação de Tony à família de origem, persuade a filha de Elisabeth à via do divórcio. Não surpreende, assim, que, reinstalada, após cada separação conjugal, na casa paterna / materna, Tony retome a participação activa nos rituais familiares, prosseguindo a luta incansável pela promoção do prestígio buddenbrookiano.

Com o mesmo empenhamento com que regista, nos cadernos de família, o seu primeiro noivado - subvertendo, pela iniciativa autónoma, a hierarquia patriarcal - reivindica Tony a sua presença na abertura do testamento paterno, providencia a decoração da primeira habitação conjugal de Thomas, anima o chefe da firma cerealífera à celebração do centenário empresarial, transporta com Hanno o quadro comemorativo do jubileu, comunica à mãe e ao irmão primogénito a enfermidade de Clara e transmite a Thomas a proposta negocial de Ralf von Maiboom, o latifundiário mecklenburguiano depauperado por dívidas de jogo.

E se o casamento da filha Erika lhe estimula o impulso de liderança, exercitado não apenas nos preparativos da cerimónia nupcial, mas também na gestão doméstica da moradia de Erika e Weinschenk, a morte da mãe anima-a à postura matriarcal. De imediato assume Tony, com soberano orgulho, a direcção dos preparativos para a cerimónia fúnebre e, embora, no salão, partilhe com Thomas e Gerda o acolhimento dos condolentes, na sala de jantar, reserva para si, para a filha e para a neta os lugares de maior destaque, relegando os restantes membros directos para lugares menos distintos. De igual modo, Tony apela, na reunião de partilhas, ao apaziguamento dos dois irmãos apartados em contundente discussão, reclama, com veemência, a Thomas que a quantia de venda da casa materna reflicta a reputação socioeconómica dos Buddenbrook e recebe, com majestática cordialidade, a visita do agente imobiliário e do potencial comprador.

Também Clara preenche o requisito burguês oitocentista de uma proveitosa união matrimonial, ao casar-se com o promissor eclesiástico Sievert Tiburtius. Porém, tão resolutamente como escolhe o parceiro conjugal, requer a filha mais nova de Elisabeth, na antevisão da morte precoce, a entrega ao viúvo da sua quota-parte no legado buddenbrookiano, desestabilizando, pela consequente discussão entre a matriarca e o chefe da firma, a harmonia, e desequilibrando, pela inerente 
dilapidação, o tesouro familiares. De resto, a morte prematura de Clara, rapariga de porte distante e jeito acre, apenas remata a evolução obstinadamente lenta de uma patologia cerebral.

Juntando, embora, ao patrónimo Buddenbrook o apelido paterno, Erika acata fielmente a delegação materna de benefício familiar. Com efeito, de alta estatura e compleição vigorosa, a filha de Tony estabelece uma vantajosa aliança nupcial, representando com esmero os papéis de esposa solícita e mãe dedicada. E, se a ingerência da mãe lhe inibe a iniciativa doméstica, a severidade patriarcal, a condenação judicial e o abandono domiciliário do marido não the fragilizam o impulso familiar e social.

Buddenbrook por afinidade, Gerda partilha com os membros femininos da família electiva o vigor - sugerido pela silhueta alta e robusta, pelo cabelo farto, pelo nariz aprumado e pelos dentes brancos, grandes e simétricos -, mas não a disposição incondicional de dignificar a imagem do clã adoptivo. É certo que a esposa de Thomas o secunda no jantar inaugurativo da moradia conjugal e na refeição oferecida a Permaneder, o acompanha na deslocação à estância termal de Bad Kreuth, o felicita, logo de manhã pelo jubileu da firma $>$ Johann Buddenbrook $<$. Verdade é, no entanto, também que Gerda se escusa a acompanhar o marido na refeição da manhã, ou nas visitas festivas aos concidadãos e que participa com manifesto desagrado na excursão familiar a Schwartau, na abertura da comemoração do jubileu, ou na derradeira celebração do Natal promovida por Elisabeth.

$\mathrm{Na}$ sua propensão artística, que, expressa em virtuosísticas execuções de violino e de piano, colide com a parca inclinação musical dos Buddenbrook, Gerda concede atenção quase exclusiva a Edmund Pfühl, o organista da Igreja de Santa Maria, a René Maria von Throta, um Segundo Tenente de Infantaria seduzido pelos matizes tonais do violoncelo, e a Hanno Buddenbrook, que, herdeiro da sensibilidade estética da mãe, com ela se inicia e sob sua vigilância se aperfeiçoa na teoria musicológica. Ao marido, Gerda nega peremptoriamente não apenas o acesso ao salão, que encerra os adereços musicais, mas também a partilha da fruição harmónico-melódica, promovendo a cisão conjugal e o apartamento de pai e filho. E, se o falecimento de Thomas estimula Gerda à venda da mansão vicarial, à cedência do recheio doméstico ao comprador e à dispensa da governanta, que acompanhou as quatro gerações familiares, a morte de Hanno encoraja a senhora ArnoldsenBuddenbrook ao abandono do território buddenbrookiano: entregando a Tony os cadernos de família, Gerda regressa à terra natal e à casa paterna, recuperando, pela fruição orgiástica da arte, a plenitude do eu.

A semelhança de Gerda, membro colateral da família protagonista, Aline Puvogel supera a cunhada na ousada determinação com que 
desvirtua o modelo patriarcal buddenbrookiano. De facto, sustentada por vários comerciantes hanseáticos, a mãe de três filhos desperta em Christian quer a prontidão para lhe saldar as despesas de entretenimento, quer a disposição de assumir a paternidade da sua filha mais nova e de a desposar a ela. Indisposta com os acessos patológicos do cônjuge, Aline diligencia o internamento vitalício do marido em instituição de saúde mental.

O impulso vital do elemento feminino evidencia-se sobremaneira no quadro final do romance: Tony, a filha Erika, as primas Klothilde, Friederike, Henriette e Pfiffi e a amiga Sesemi reúnem-se em casa de Gerda, para se despedirem da viúva Buddenbrook. Faltam Christian, o único sobrevivente masculino da família titular, recluso em espaço psiquiátrico, e Aline, a esposa social, mas não familiarmente reconhecida. Após pausada reflexão sobre o retorno da anfitriã à urbe natal e sobre a recente morte de Hanno, Gerda entrega à cunhada os cadernos de família, até aí, por tradição secular, na posse do varão Buddenbrook em função patriarcal. Incansável guardiã da memória familiar, a neta de Johann Buddenbrook sénior reafirma, então, o propósito de preservar a união do clã, anunciando gestos ritualísticos de harmonia e coesão familiares.

Tal reunião de figuras vinculadas por laços de parentesco e de amizade e pertencentes ao mesmo sexo recorda os encontros dos irmãos Thomas e Christian com os companheiros Döhlmann, Gieseke e Gosch, na confeitaria do parque termal, em Travemünde. E, todavia, ao desencanto abúlico dos cinco cavalheiros contrapõe-se a energia optimista das oito mulheres, que assistem, como Heidy Margrit Müller (1991: 143) sublinha, vacilantes, mas, pertinazes, ao definhamento da patrilinearidade.

\section{A dupla óptica manniana}

A claudicação do masculino e a afirmação do feminino manifestase por de mais na relação inversamente proporcional da taxa de natalidade ao longo das quatro gerações buddenbrookianas: à preponderância de filhos varões sucede a supremacia numérica de filhas. Deste modo, enquanto a segunda geração se caracteriza por dois rapazes e uma rapariga, a terceira distingue-se por dois rapazes e duas raparigas e a quarta compõe-se de um rapaz e uma rapariga, sendo que Tony concebe uma segunda filha, que sucumbe à nascença, e Christian assume a paternidade de uma criança alegadamente sua filha. Já sem o apelido Buddenbrook, a neta de Tony forma sozinha a geração subsequente.

Testemunho da debilitação masculina e da pujança feminina constitui paralelamente o distinto índice de mortalidade buddenbrookiana. De facto, 
se os varões Buddenbrook falecem em idade crescentemente inferior, a morte de Elisabeth, aos sessenta e oito anos, corrige o falecimento precoce da filha Clara, aos vinte seis. Ademais, somente na primeira geração o patriarca sobrevive à esposa. E, enquanto a perda conjugal promove a desistência vivencial de Johann Buddenbrook sénior, a viuvez possibilita a Elisabeth a afirmação da interioridade e permite a Gerda a libertação do eu.

E, contudo, Buddenbrooks não apresenta nem um processo unilinear de declínio familiar, nem um movimento exclusivo de decadência masculina e supremacia feminina. Na verdade, o primeiro romance de Thomas Mann relativiza ironicamente o subtítulo, expondo, por um lado, não a "decadência de uma família", antes a falência e a ascensão de diversas famílias, e questionando, por outro lado, a imagem contrapontística dos géneros.

Antes de mais, o elemento feminino sobrepõe-se ao elemento masculino no domínio bio-psíquico, mas não no aspecto económico-social: o tableau que encerra a obra apresenta sete mulheres da família Buddenbrook que lesaram o património e a reputação familiares, e se movem, pela marca estigmatizante do divórcio, do celibato e da viuvez, na periferia do estrato alto-burguês. Significativamente, três residem na zona extra-mural do burgo, uma retorna em breve à casa paterna, em região além-fronteiriça, e das quatro domiciliadas no núcleo urbano uma habita em instituição monástica de assistência às herdeiras desafortunadas de famílias distintas. De resto, nenhuma das principais representantes da família titular goza de completa saúde: Tony enferma de cíclicas perturbações gástricas, Clara, provavelmente estéril, morre prematuramente por doença cerebral e Gerda, de fisionomia pálida e olheirenta, tem gravidez tardia.

Concomitantemente, os varões Buddenbrook denunciam, a par do enfraquecimento vital, crescente busca do apoio feminino: Jean, na festa da inauguração, desabafa à mãe a sua apreensão perante a carta reivindicativa que o meio-irmão dirigiu ao pai; Thomas, na comemoração do jubileu, entrega-se frágil ao abraço com que a mãe o felicita; Hanno, que já na fisionomia, na silhueta e no temperamento revela traços de feminilidade, refugia-se no aconchego da avó, da mãe, da tia e da governanta e rende-se à passionalidade viril do colega Kai Mölln. ${ }^{4}$

${ }^{4}$ Walter Erhart (2001: 293-294) defende que a postura receptiva de Thomas, na leitura de Schopenhauer, e de Hanno, na derradeira execução pianística, denuncia traços de feminilidade. 
A influência da figura feminina sobre os varões Buddenbrook patenteia-se, desde logo, na prontidão com que Jean acata a sugestão de Madame Antoinette de que o filho adie a entrega ao pai da carta de Gotthold; na cedência de Jean à proposta da esposa de contratar um criado suplementar; na anuência de Thomas à solicitação de Elisabeth de colocar o filho mais novo na firma $>$ Johann Buddenbrook<; ou na aceitação por Christian do emprego proposto; e revela-se sobremaneira no caso de Hanno, que, herdando a sensibilidade musical de Gerda, vê a sua dedicação à música fomentada pela mãe, que providencia a colocação no quarto do filho de uma gravura com o retrato de Giacomo Meyerbeer circundado por personagens das suas óperas e lhe proporciona aulas de piano e a ida a espectáculos operáticos, pela avó, que lhe oferece um harmónio e um teatro de marionetas com a cena conclusiva de Fidelio, e pela tia, que compara o sobrinho a Mozart e Meyerbeer.

E, todavia, ao decréscimo vital dos varões Buddenbrook contrapõe-se o seu progressivo apuramento cognitivo e emocional-afectivo: seduzidos respectivamente pela religião, pela pintura, literatura e filosofia, pelo teatro e o circo e pela música, Jean, Thomas, Christian e Hanno perscrutam, com crescente clarividência, a superficialidade e a estreiteza da prática burguesa, resvalando para a margem da sociedade dinâmica e produtiva.

O leitor atento e, ademais, familiarizado com a óptica irónico-distanciadora de Thomas Mann, que apura a antinomia finissecular de mundividência burguesa e predisposição artística, reconhece que a família Buddenbrook sucumbe ao modelo patriarcal oitocentista, que sobrestima os varões primogénitos, ampliando-lhes as tarefas, menospreza os membros masculinos não primogénitos, ignorando-lhes as competências, e desconsidera os elementos femininos, contendo-lhes as iniciativas. Deste modo, Elisabeth vê a sua função matriarcal limitada pelo estatuto vicarial de Thomas, enquanto Christian e Tony sofrem o tratamento infantilizante com que o irmão lhes trava os gestos de autonomia: incondicionalmente obediente à ética patriarcal, Thomas assume o papel de marido na discussão com a mãe sobre a herança de Clara e representa o papel de pai, tanto no confronto com Christian sobre a pretensão nupcial do irmão, como no diálogo com Tony sobre a segunda separação conjugal da irmã. ${ }^{5}$

Em resumo, Jean claudica no cumprimento obstinado das incumbências paternas; Christian não resiste aos espartilhantes códigos familiares; Hanno sucumbe à dilacerante contraposição de delegações

${ }^{5}$ Mais acentuada do que em Antoinette, em Elisabeth, em Clara, ou em Erika, a comicidade de Tony deriva, como nota Elisabeth Boa (1995: 131), da discrepância entre a posição que a figura ocupa no sistema patriarcal e o grau da sua assertividade. 
maternas e paternas; Thomas cede sob os conflitos que eclodem no próprio eu. Tony sobrevive na encenação alienatória de gestos anacrónicos, com a adjuvância da filha, das primas e da amiga. Resta saber se Gerda, regressada ao território paterno, supera, pelo diálogo musical com o progenitor, o modelo que aniquila a família Buddenbrook.

\section{BIBLIOGRAFIA}

BOA, ELISABETH, 'Buddenbrooks'. Bourgeois Patriarchy and fin-de-siècle Eros, In: Michael Minden (ed.), Thomas Mann. London, New York, Longman, p. 125-142, 1995.

ERHART, WALTER, Familienmänner. Über den literarischen Ursprung moderner Männlichkeit. München, Fink, 2001.

ERHART, WALTER, Thomas Manns 'Buddenbrooks' und der Mythos zerfallender Familien. In: Claudia Brinker-von der Heyde und Helmut Scheuer (Hg.), Familienmuster - Musterfamilien. Zur Konstruktion von Familie in der Literatur. Frankfurt am Main, Lang, p. 161-184, 2004.

HERD, ERIC. Ehe und Familie. In: Ken Moulden und Gero von Wilpert (Hg.), Buddenbrooks-Handbuch. Stuttgart, Kröner, p. 213-228, 1988.

LINDTKE, GUSTAV, Geselliges Leben. In: Lübeck zur Zeit der Buddenbrooks. Lübeck, Museum für Kunst und Kulturgeschichte der Hansestadt Lübeck, p. 50-52, 1975.

LINDTKE, Gustav. Die Stadt der Buddenbrooks. Lübecker Bürgerkultur im 19. Jahrhundert. 2. überarbeitete und erweiterte Auflage, Lübeck, Verlag Max Schmidt-Römhild. Mann, Thomas (1990a) Gesammelte Werke in dreizehn Bänden. Band I, Frankfurt am Main, Fischer Taschenbuch Verlag, 1981.

MANN, THOMAS, Über die Ehe. In: T. M., Gesammelte Werke in dreizehn Bänden. Band X, Frankfurt am Main, Fischer Taschenbuch Verlag, p. 191$-207,1990 \mathrm{~b}$.

MÜLLER, HEIDY MARGRIT, Töchter und Mütter in deutschsprachiger Erzählprosa von 1885 bis 1935. München, iudicium, 1991.

ROESSLER, NORMAN, Clio in the Midst of Patriarchy: Tony Buddenbrook and the Mediation of the Buddenbrook Family Past. Focus on Literature 2 (2). 149-154, 1995.

TOBIN, PATRICIA DRECHSEL, Time and the Novel. The Genealogical Imperative. Princeton, N. J., Princeton University Press, 1978.

VOGT, JOCHEN, Thomas Mann: «Buddenbrooks». München, Fink, 1983. 